\title{
Archéopages
}

Archéopages Archéologie et société

$46 \mid 2018$

Maisons

\section{Poubelles de militaires}

\section{Emmanuel Barthélémy-Moizan}

\section{(2) OpenEdition}

Journals

Édition électronique

URL : https://journals.openedition.org/archeopages/4615

DOI : 10.4000/archeopages.4615

ISSN : 2269-9872

\section{Éditeur}

INRAP - Institut national de recherches archéologiques préventives

\section{Édition imprimée}

Date de publication : 1 décembre 2018

Pagination : 108-109

ISSN : 1622-8545

\section{Référence électronique}

Emmanuel Barthélémy-Moizan, «Poubelles de militaires », Archéopages [En ligne], 46 | 2018, mis en ligne le 01 décembre 2020, consulté le 08 juin 2021. URL : http://journals.openedition.org/ archeopages/4615; DOI : https://doi.org/10.4000/archeopages.4615 


\section{Poubelles de militaires}

Emmanuel Barthélémy-Moizan Inrap, responsable d'opération, EA 929 " $A I H P-G E O D E$ »

Site

Fort Louis

Marigot

Saint-Martin

Date

Octobre-décembre 2016

Surface

$5300 \mathrm{~m}^{2}$

Équipe

Étude documentaire

Stéphanie Dargaud

Collectivitéde Saint-Martin

Étude du mobilier céramique et du verre

Fabrice Casagrande

Inrap

Étude du mobilier métallique

et de la faune

Alexandre Coulaud

Inrap

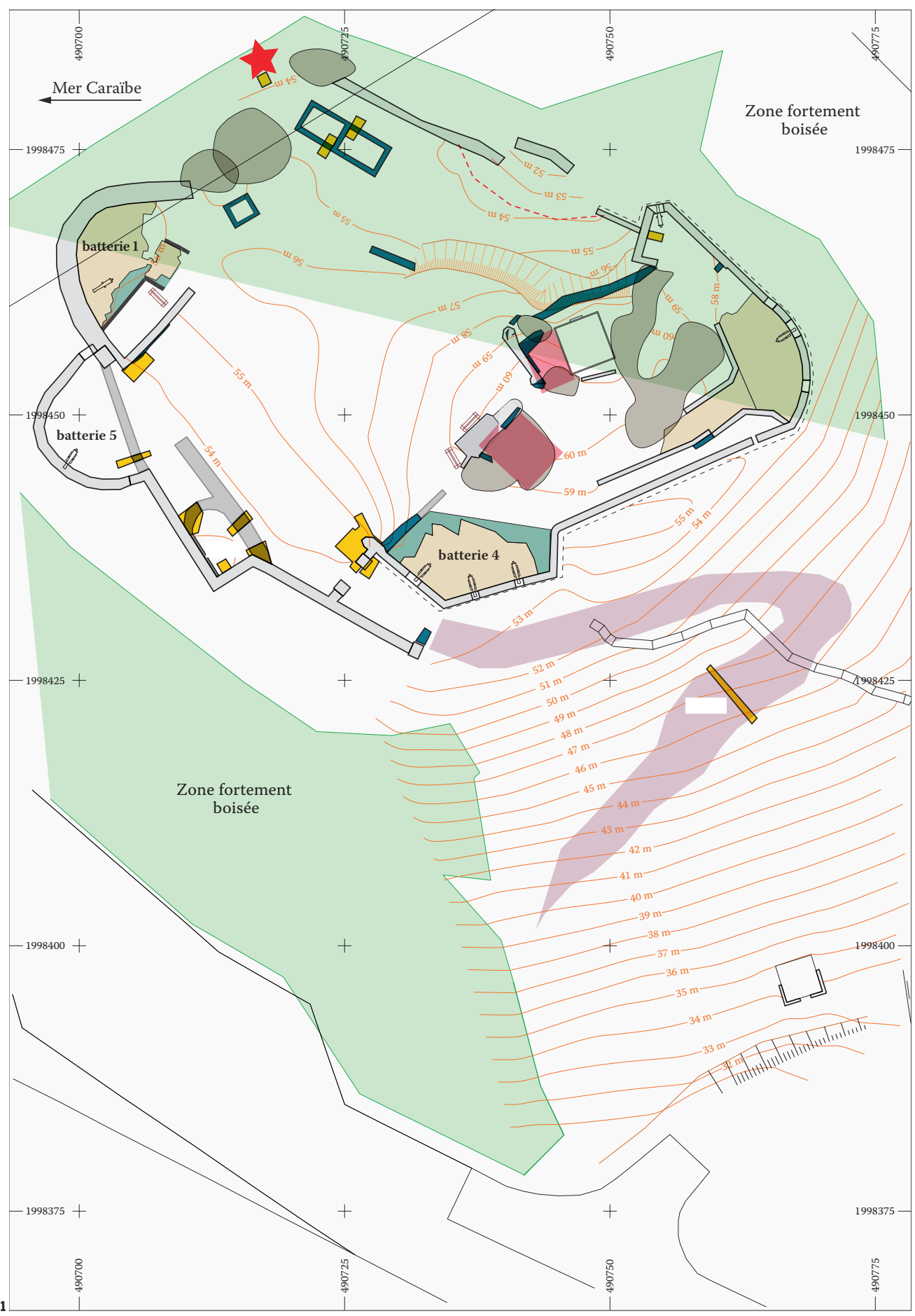

1. Plan général du site,

implantation des sondages

et proposition de restitutions

des vestiges du fort.

2. Pot de chambre en faïence

stannifère provenant

de la péninsule lbérique.
3. Marmite en poterie commune non tournée, de facture artisanale et communément nommée aux Antilles françaises Coco-nég. Ce type de céramique

antillaise se rencontre dans toutes les Antilles notamment sur les îles anglaises comme Saint-Thomas, Saint-Jean, Saint-Christophe ou encore Saint-Vincent. À Sainte-Croix elles sont appelées AfroCruzan'ware, à la Jamaïque,

Afro-jamaican'ware. 
Sur l'île de Saint-Martin, le Fort Louis, construit sur un morne en bordure de littoral, surplombe la ville de Marigot, implantée sur la côte nord caraïbe. C'est à partir de la deuxième moitié du XVIII ${ }^{\mathrm{e}}$ siècle que la ville se développe véritablement sous l'impulsion du commandant Descoudrelles, nommé en 1764à la tête de cette colonie française. Le fort, édifié en 1789 par le gouverneur Durat, successeur de Descoudrelles, assurait jusqu'à la fin du XIX ${ }^{e}$ siècle la défense des entrepôts du port, où étaient stockées les productions locales (sel, café, sucre de canne, rhum). Fortin de bois à l'origine, la fortification n'a de cesse d'évoluer jusqu’à s'étendre, au début du $\mathrm{XIX}^{\mathrm{e}}$ siècle, au bas des pentes avec la construction de deux batteries en poste avancé, côté mer. Au début du $\mathrm{xx}^{\mathrm{e}}$ siècle, le complexe militaire perd sa fonction et tombe en ruines, avant d'être totalement laissé à l'abandon. Inscrit au titre des Monuments historiques depuis le 7 juillet 2011, le site fait l'objet d'un vaste programme d'aménagement et de valorisation
(2017-2019). C'est dans ce contexte qu'une expertise archéologique (Barthélémy-Moizan et al., 2017) a été réalisée sur l'enceinte haute $\mathrm{du}$ fort et une partie du versant oriental du morne [ill. 1]. Le diagnostic a montré que seuls quelques rares secteurs du fort sont érodés de manière définitive. La majorité du site conserve des éléments révélateurs : le rocher affleurant dans certains secteurs porte encore les empreintes des occupations successives ; les zones de terrasses, au nord et au sud-est, restent préservées; les maçonneries en place et en élévation fournissent de nombreux indices sur l'évolution du site.

La confrontation des données historiques avec celles issues de l'archéologie a permis de proposer une nouvelle lecture du site et d'apporter des éléments inédits de réflexion pour la compréhension de ce complexe militaire (BarthélémyMoizan, Dargaud, à paraître). Létude de la documentation historique en 2017 (et qui se poursuit, notamment aux Archives nationales d'outre-mer et aux Archives départementales de la Guadeloupe) s'appuie sur des séries produites entre la deuxième moitié du XVIII ${ }^{e}$ siècle et le début du $\mathrm{xx}^{\mathrm{e}}$ siècle. Cependant, si les éléments sont relativement abondants pour la période de la souveraineté française, aucun document illustrant les épisodes de l'occupation anglaise n'a été retrouvé. Les troupes anglaises ont pourtant occupé lîle de SaintMartin à quatre reprises entre la fin du XVIII ${ }^{\mathrm{e}}$ siècle et le début du XIX ${ }^{\mathrm{e}}$ siècle : en 1781-1783, 1794, 1800 et entre 1810 et 1815 , dans le cadre des guerres napoléoniennes dans
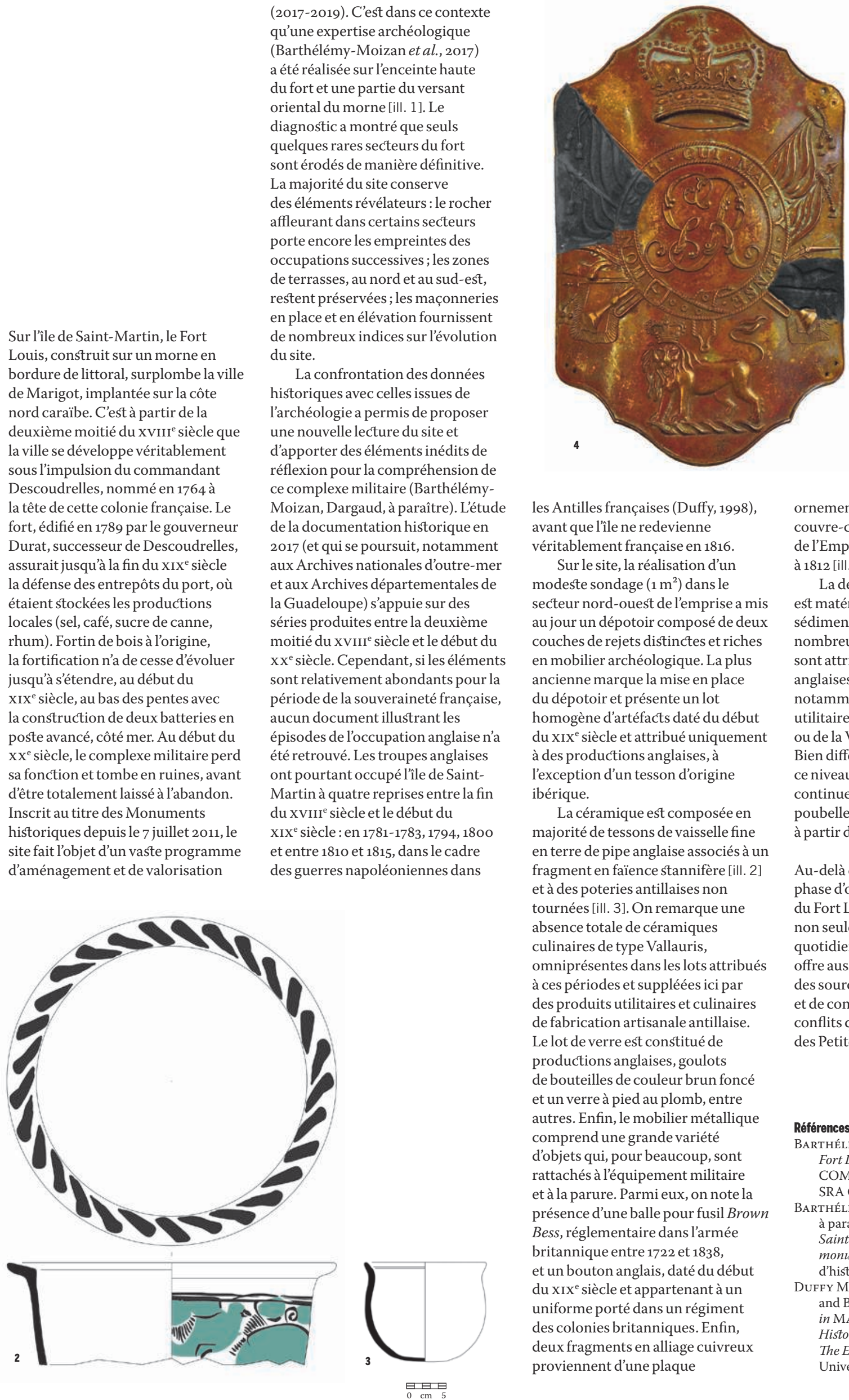

4. Localisation (en gris) des fragments de plaque d'ornement retrouvés. Ces plaques étaient fixées sur le devant des stovepipes portés par les soldats des régiments d'infanterie de ligne britannique durant les guerres napoléoniennes. Le modèle retrouvé présente un décor assez complet, arborant un ensemble d'emblèmes de la royauté britannique.

les Antilles françaises (Duffy, 1998), avant que l'île ne redevienne véritablement française en 1816.

Sur le site, la réalisation d'un modeste sondage $\left(1 \mathrm{~m}^{2}\right)$ dans le secteur nord-ouest de l'emprise a mis au jour un dépotoir composé de deux couches de rejets distinctes et riches en mobilier archéologique. La plus ancienne marque la mise en place du dépotoir et présente un lot homogène d'artéfacts daté du début du XIX ${ }^{e}$ siècle et attribué uniquement à des productions anglaises, à l'exception d'un tesson d'origine ibérique.

La céramique est composée en majorité de tessons de vaisselle fine en terre de pipe anglaise associés à un fragment en faïence stannifère [ill. 2] et à des poteries antillaises non tournées [ill. 3]. On remarque une absence totale de céramiques culinaires de type Vallauris, omniprésentes dans les lots attribués à ces périodes et suppléées ici par des produits utilitaires et culinaires de fabrication artisanale antillaise.

Le lot de verre est constitué de productions anglaises, goulots de bouteilles de couleur brun foncé et un verre à pied au plomb, entre autres. Enfin, le mobilier métallique comprend une grande variété d'objets qui, pour beaucoup, sont rattachés à l'équipement militaire et à la parure. Parmi eux, on note la présence d'une balle pour fusil Brown Bess, réglementaire dans l'armée britannique entre 1722 et 1838 , et un bouton anglais, daté du début du XIX ${ }^{e}$ siècle et appartenant à un uniforme porté dans un régiment des colonies britanniques. Enfin, deux fragments en alliage cuivreux proviennent d'une plaque ornementale d'un stovepipe, couvre-chef utilisé dans les armées de l'Empire britannique de 1803 à 1812 [ill. 4].

La deuxième phase de rejet est matérialisée par une couche sédimentaire contenant de nombreux tessons dont les faciès sont attribués à des productions anglaises et françaises avec notamment la présence des poteries utilitaires ou culinaires de Vallauris ou de la Vallée de l'Huveaune. Bien différencié en stratigraphie, ce niveau montre que ce secteur continue à être utilisé comme poubelle lors du retour des Français à partir de 1816.

Au-delà d'illustrer cette courte phase d'occupation britannique du Fort Louis, le mobilier exhumé non seulement renseigne sur la vie quotidienne d'un site militaire, mais offre aussi un aperçu de l'alternance des sources d'approvisionnement et de consommation au gré des conflits qui ont marqué les territoires des Petites Antilles.

Références bibliographiques

BARTHÉLÉMY-Moizan E. et al., 2017, Fort Louis, Marigot, Saint-Martin, COM, rapport d'opération, InrapSRA Guadeloupe, $169 \mathrm{p}$.

BARThÉLÉMY-MoIZAN E., DARGAud S., à paraître, Le Fort Louis (Marigot, Saint-Martin), redécouvrir un monument historique de l'île, Société d'histoire de la Guadeloupe.

Duffy M., 1998, « World-Wide War and British Expansion, 1793-1815 ", in Marshall P. J. (éd.), The Oxford History of the British Empire, vol. II, The Eighteenth Century, Oxford University Press, p. 207-230. 